\title{
The impact of absorbed and unabsorbed slack on firm profitability: Implications for resource redeployment
}

\begin{abstract}
Authors:
Josep $\mathrm{M}^{\mathrm{a}}$. Argilés-Bosch Universitat de Barcelona (Department of Business). Josep Garcia-Blandon IQS School of Management, Universitat Ramon Llull. Monica Martinez-Blasco IQS School of Management-Universitat Ramon Llull.
\end{abstract}

\begin{abstract}
This study undertakes an empirical analysis of the impact of absorbed and unabsorbed slack, employing three different measures for each slack type, on firm profitability. We find that unabsorbed slack has a more favorable influence on future firm profitability than absorbed slack. While all the absorbed slack indicators have a significant negative influence on future profitability, the three unabsorbed slack indicators present positive, negative and non-significant influences, respectively. The fewer constraints on the redeployment of unabsorbed slack to exploit new opportunities point to its comparative advantage over absorbed slack. We find evidence for the differential impact of absorbed vs. unabsorbed slack on profitability in firms with lower levels of slack, which suggests firms prefer to withdraw resources from current business and redeploy them to develop new and more favorable business opportunities.
\end{abstract}

Keywords: absorbed slack, unabsorbed slack, resource redeployment, profitability, financial performance.

Acknowledgements: We acknowledge the interesting and valuable comments and feedback received from all participants in the special conference on "Corporate strategy and resource redeployment" held in Strasbourg from November $1^{\text {st }}$ to $3^{\text {rd }}, 2015$, and specially to Timothy Folta and Will Mitchell 


\section{The impact of absorbed and unabsorbed slack on firm profitability: Implications for resource redeployment.}

\section{INTRODUCTION}

Firms want to grow. There are well-known inducements to encourage firm growth, such as increasing demand for certain products; introducing technological changes that call for production on a larger scale; exploiting discoveries; taking advantage of opportunities to obtain a better market position; and, seeking protection against adverse environmental changes, etc. (see Penrose, 1995, p. 65-66). Bercovitz and Mitchell (2007) claim that growth in both scale and scope enhances a business's long-term survival, owing to the greater availability of financial resources, organizational routines, and external ties. Indeed, there is a sizable body of research indicating that large firms and businesses tend to survive longer than smaller companies (e.g. Mitchell, 1994; Baum, 1996). Managers exploit resources to pursue their firms' general and, more specific, growth objectives, and to do so they first use existing resources. In this regard, Cyert and March (1956, p. 52) have defined this pool of excess resources, which enables firms to adjust to unexpected fluctuations, as 'slack'. Bourgeois (1981) similarly states that slack is a cushion of actual and potential resources that firms can use to adapt to internal and external pressures, counter threats and exploit opportunities. Despite claims that it is a somewhat nebulous construct (Daniel et al., 2004), slack serves as a useful indicator of a firm's resources. Likewise, slack can create opportunities for new investments, allowing managers to recognize opportunities and to recombine existing resources into new capabilities. Kaul (2012) found that new knowledge developed through innovation prompted a redeployment of scarce resources into previously unexplored areas of opportunity. In turn, new investments offer potential for better performance.

Financial resources are often needed to complement the redeployment of strategic resources. For example, resources may have to be adjusted for use in a new context, or additional resources may have to be acquired to complement the reallocated resources. In this sense, slack is closely associated with the availability of financial resources. Here, we investigate how slack affects firm profitability.

A distinction can be drawn between absorbed and unabsorbed slack in relation, respectively, to excess costs in organizations with low discretionary use, and 
uncommitted resources allowing greater managerial discretion. We expect they have different implications for resource redeployment and, hence profitability. On the one hand, absorbed slack is associated with constrained resources, which, precisely because of their constraints, are restricted in their use to the firm's current business and cannot be converted into alternative uses. The more specific a resource is, the lower its value when applied to its second-best use (Montgomery and Wernefelt, 1988). While absorbed slack can be readily used to expand current business, it is less suited to resource redeployment than unabsorbed slack. In contrast to absorbed slack, firms can more readily redeploy unabsorbed slack and commit it to use. While unabsorbed slack can also be used to expand extant business, what distinguishes it from absorbed slack is its comparatively greater potential for sharing and, consequently, for allowing synergies, as well as its comparatively greater potential for being applied to alternative businesses. In this respect, the distinction between absorbed and unabsorbed slack might provide some interesting insights to resource redeployment. Unabsorbed slack also provides more potential than absorbed slack for recombining resources in new ways.

The redeployment of resources can contribute to improving profitability by providing access to more profitable businesses than the current business. Moreover, the failure to exit a declining business in a timely fashion can degrade the overall performance of the firm (Sull, 1999), while firms may, through redeployment, benefit from exiting markets with declining opportunities and by taking advantage of new opportunities in other markets (Penrose, 1995). Redeployment of resources also underpins the reconfiguration of businesses, which in turn may fuel firm growth (Seth, 1990; Capron et al., 1998). When current businesses are stagnating the firm can withdraw these resources to redeploy them in alternative businesses with higher marginal outcomes in terms of growth.

This study seeks to contribute to the analysis of the impact of slack on profitability, and to link slack with research in resource redeployment. We use three different indicators of both absorbed and unabsorbed slack and perform our study with a panel data for a sample of firms with at least twenty years of observations in COMPUSTAT. We find that unabsorbed slack has a more favorable impact on profitability than absorbed slack. While all the absorbed slack indicators present a significant negative influence on future profitability, the three unabsorbed slack indicators present positive, negative and non-significant influences, respectively. The fewer constraints on the redeployment of unabsorbed slack to exploit new opportunities, as well as to achieve 
synergy through resource sharing, point to its comparative advantage over absorbed slack. We find evidence for the differential impact of absorbed vs. unabsorbed slack on profitability in firms with lower levels of slack, which suggests managers prefer to withdraw resources from current business and redeploy them to develop new business. However, there may be alternative explanations as to why slack impacts profitability, which we cannot rule out.

The rest of the paper is organized as follows: the next section outlines the research background and formulates the study's hypothesis. We then explain the research design and results, and end by offering our concluding remarks.

\section{RESEARCH BACKGROUND AND HYPOTHESIS}

\section{Unabsorbed vs. absorbed slack}

Most authors draw a distinction between absorbed and unabsorbed slack (e.g. Tan and Peng, 2003; Lin et al., 2009). Alternative classifications of slack rely also on degrees of managerial resource use in relation to both types of slack (e.g. George, 2005; Bradley et al., 2011a; Bradley et al., 2011b). The most common and accepted difference between both types of slack relies on the George's (2005) concepts of high-discretion and low-discretion managerial use respectively. Absorbed slack is defined as excess costs of unused capacity with low discretionary use, while unabsorbed slack is uncommitted resources in an organization that managers have high discretion to redeploy and commit them to new uses (e.g. Huang and Li, 2012; Tan and Peng, 2003). The former is associated with excess resources that cannot be flexibly allocated to opportunistic ways that are unrelated to organizational routines, while the later refers to flexible pool of unused resources that can be allocated to unpredictable opportunities (Mishina et al., 2004; Tan and Peng, 2003).

Likewise, we can distinguish between different degrees of resource constraints. The most constrained resources are restricted in use and can preferably be exploited for current business. They can be used to feed or expand current business, but given their limitations they hardly can be withdrawn from their current uses and redeployed to alternative uses. In contrast, less constrained resources are readily redeployed to new 
uses. Similarly, less constrained resources can be more easily shared with different businesses than more constrained resources. Figure 1 illustrates these relationships.

(Insert Figure 1 approximately here)

Thus, absorbed slack is most closely associated with constrained resources, while unabsorbed slack is associated with unconstrained resources, allowing low and high discretionary uses respectively. At the same time, there are different degrees of constraints affecting absorbed and unabsorbed slack. Finished products are a good example of the most constrained resources within a firm's absorbed slack. Once manufactured, they can almost exclusively be used to expand sales in current markets. Machines and equipment are another example of absorbed slack, but these resources are less constrained than finished products. While they can be used to manufacture current products (thus expanding current business), they can also be shared with newly designed, but related, markets and products, although they are less likely to be applied to completely new businesses. Similarly, while qualified personnel and managerial teams are more highly skilled and trained for their current commitments, they may also be engaged on other assignments within the firm. Likewise, they can be trained to perform new business, but such redeployment often encounters greater difficulties. The lack of financial resources may prevent a firm from responding to new market opportunities, while access to financial resources can serve to alleviate the constraints on new ventures. Kraatz and Zajac (2001) found that greater financial resources allow firms to move into a new market as soon as opportunities arise. In this vein, financial resources - a typical example of unabsorbed slack - can be readily redeployed, and among such resources the equity-to-debt ratio is more readily redeployed than working capital, given that the former is a good indicator of the affordability of resources for long-term, new ventures, while the latter is a better indicator of short-term, more pressing commitments.

Absorbed and unabsorbed slack, therefore, are resources that can be devoted to expanding the existing business or to sharing, as well as to redeployment. Unabsorbed slack allows greater resource redeployment and synergies than absorbed slack, while the latter is less suited to redeployment. Finally, given that there are different gradations of absorbed slack, the less it is constrained the more it is suited to achieving synergies through resource sharing. 


\section{Implications of slack on profitability}

Organizational theory holds that slack resources have a positive effect on firm performance (Tan and Peng, 2003; Daniel et al., 2004; George, 2005). According to the theory, a certain level of excess resources provides flexibility to experiment, take risks and undertake proactive initiatives. Firms use this slack to build capabilities that make them competitive while allowing them to make strategic choices. Slack acts as a buffer in periods of economic difficulties, facilitating adjustment in the face of unanticipated contingencies. Surplus resources make it easier for firms to pursue their projects. Thompson (1967) argued that slack provides a reactive bulwark against threats and facilitates proactive strategic initiatives. According to Sharfman et al. (1988), slack enables firms to survive in a turbulent environment. Although slack may entail a surplus cost, organizational theory considers that the benefits of slack outweigh its costs (Tan and Peng, 2003). Damanpour (1987) and Greve (2003) argued that slack has a positive effect on innovation. Firms with no surplus resources are more constrained in their dealings with operational issues. Managers and employees direct their efforts to addressing urgent matters and tend to rush orders. Coordination, planning, process improvement, innovation, market research, etc. are set aside, or may not be properly dealt with. However, the effect of slack on profitability is uncertain. According to Phan and Hill (1995) the use of scarce resources has an immediate positive impact on a firm's income, in the case of firms using their surplus resources, as well as reducing the amount of investment used for firm activity. The subsequent effect is an improvement in firm profitability through an increase in income and a reduction in the investment in resources (Starr and MacMillan, 1990). Sinclair et al. (2000) argued that firms with excess capacity have limited incentives to experiment. Stevenson and Jarillo (1990) suggested that resource slack entices managers to be administrative rather than entrepreneurial in their management approach. They become complacent and risk averse. Idle resources induce inefficiency. Baker and Nelson (2005) argued that firms with fewer resources are likely to leverage them efficiently. According to these authors, scarcity induces managers to improve their efficiency of use, while surplus resources induce waste and do not favor efficient use, thus reducing profitability.

Results from empirical research have found a positive relationship between slack and profitability (e.g. Peng et al., 2010; Su et al., 2011; Vanacker et al., 2013), a negative 
relationship (e.g. Subramanyam et al., 2012), and also contradictory influences depending on the type of slack (e.g. Tan and Peng, 2003; George, 2005; Tan and Wang, 2010). Most previous research analyzed only a single (e.g. O'Brien and Folta, 2009; Love and Nohria, 2005; Mellahi and Wilkinson, 2010) or different measures of slack without considering the distinction between absorbed and unabsorbed (e.g. Tan, 2003; Mishina et al, 2004; Modi and Mishra, 2011; Bradley et al., 2011b), but those studies distinguishing between both types of slack (e.g. Tan and Peng, 3002; Huang and Li, 2012) did not focus on analyzing their differential effects on performance.

While the relationship between slack and profitability is uncertain, the differential effect of unabsorbed vs. absorbed slack on profitability can be more precisely hypothesized. Helfat and Eisenhardt (2004) explained the concept of inter-temporal economies of scope, discussing how resources from mature, declining, or defunct businesses can be reallocated quickly to more promising product-market opportunities. With respect to resource characteristics, we argue that unabsorbed slack has a differential advantage in terms of the opportunities for redeployment compared to absorbed slack. Matusaka (2001) argued that because organizational capabilities are at the source of a company's value, managers continuously search for better opportunities to ensure the survival of the firm, freeing up managerial resources and other productive factors from current uses to new businesses. Wealth creation depends in large measure on the identification of new opportunities and organizing effectively and efficiently to embrace them (Teece et al., 1997; Sirmon and Hitt, 2009). In this vein, firms with unabsorbed slack are more ready to divert from current, unprofitable businesses to better opportunities, thus contributing more favorably to profitability than absorbed slack. We therefore formulate the following hypothesis:

Hypothesis: Unabsorbed slack has a more positive (or less negative) influence on future profitability than absorbed slack.

\section{RESEARCH DESIGN}

\section{Equation and dependent variables}

In this study we analyze the impact of a wide array of slack indicators on profitability. To do so we use the following equation, which formulates profitability at 
time $t+1$ depending on different indicators of slack $(S L)$ at time $t$, and controlling also for sales growth, size, industry profitability and growth, as well as for specific seasonal or temporal effects:

$$
\begin{aligned}
R O A_{i, t+1}=\alpha_{0} & +\sum_{j=1}^{J} \alpha_{j} \cdot S L_{i, t}+\alpha_{s} \cdot \frac{S_{i, t+1}}{S_{i, t}}+\alpha_{z} \cdot \log A S S_{i, t}+\alpha_{r} \cdot I P R_{i, t}+\alpha_{c} \cdot I S C_{i, t+1} \\
& +\sum_{t=1}^{T} \alpha_{t} \cdot Y_{\mathrm{i}, t}+\varepsilon_{i, t}
\end{aligned}
$$

where all the variables refer to firm $i$ in year $t, S$ indicates sales, $A S S$ is firm size measured as total assets, IPR indicates industry profitability, ISC represents the increase in industry sales with respect to the previous year, $Y$ is a dummy variable indicating that an observation belongs to a given year (with value 1, and zero otherwise), $j, s, z, r$ and $c$ are the subscripts for the estimators of slack, sales growth and size, industry profitability and the increase in sales, respectively, and $\varepsilon$ is the error term. For the sake of simplicity, we use this last symbol to indicate the error term in all the equations in this paper.

We use return on assets $(R O A)$ as an indicator of profitability, referring primarily to the economic profitability of firms and indicating how many dollars of earnings they derive from each dollar of assets they control. The indicator has been widely used in previous research (Daniel et al., 2004), and more recently in Tan and Peng (2003), Tan and Wang (2010) and Modi and Mishra (2011) among others.

\section{Measures of absorbed and unabsorbed slack}

As discussed, slack can be defined as the pool of resources in an organization that is in excess of the minimum necessary to produce a given level of organizational output. Extant research has identified different types of slack. George (2005), for example distinguishes between high-discretion, low-discretion, and transient slack. Bradley et al. (2011a) employ indicators of potential, recoverable, and high-discretion slack, while Bradley et al. (2011b) use alternative measures of potential, absorbed and highdiscretion slack. Tan and Peng (2003) and Huang and Li (2012) distinguish between absorbed and unabsorbed slack to refer, respectively, to excess costs in organizations 
with low discretionary use and uncommitted resources allowing greater managerial discretion. Unlike absorbed slack, firms can readily redeploy unabsorbed slack and commit it to use. This last distinction is the most commonly used and the most appropriate for our purposes here, given that it captures the constraints on the resources making up the slack. In order to include as wide an array of slack measures as possible in our study, we adopt three indicators for each slack type. Frequently employed elsewhere in the literature, for absorbed slack, we use the ratios of inventories to sales (INVSL), of property, plant and equipment (PPE) to sales (PPESL) and selling, general and administrative expenses (SGA) to sales (SGASL), while for unabsorbed slack, we use measures of financial slack, equity-to-debt ratio, and cash slack (FINSL, EQDSL and CASHSL respectively).

Inventories, PPE, and SGA have been previously and similarly used as measures of absorbed slack (e.g. Hendricks et al., 2009; Love and Nohria, 2005; Modi and Mishra, 2011). FINSL has been widely used in previous studies. In line with Mishina et al. (2004) and Bradley et al. (2011b), we define it here as the difference between working capital available and working capital required, and we take its relative value with respect to total assets. More precisely, we calculate it as a ratio of current assets less current liabilities to total assets. EQDSL has also been widely used in previous studies (e.g. Vanacker et al., 2013; George, 2005; Bradley et al., 2001a, 2011b). We calculate it as the ratio of stockholders equity to current liabilities and long term debt. While the aforementioned authors describe it as potential or high-discretion slack, George (2005) uses the ratio of debt-to-equity as a measure of low-discretion slack. We consider it as allowing high discretionary use, given that the measure does not involve a specific asset or resource endowment. Vanacker et al. (2013), Bradley et al. (2011a) and George (2005) each use different measures of cash slack; here, we define CASHSL as cash and short-term investments to total assets.

We forward profitability to time $t+1$ to capture more effectively the effects of slack and to help establish the direction of causality.

\section{Control variables}

In the traditional model of cost behavior, costs are described as fixed and variable with respect to activity. Given that only variable costs are immediately related to changes in sales, the increase/decrease in sales in a given period significantly influences 
firm profitability (Anderson et al., 2003). We expect an immediate positive influence of sales growth on firm profitability.

Size is an important factor influencing firm performance. It is widely recognized that large firms enjoy certain advantages over small firms, including economies of scale (e.g. Caves and Barton, 1990; Alvarez and Crespi, 2003), more favorable access to the credit market and lower financing costs (e.g. Beck and Demirguc-Kunt, 2006; Martinelli, 1997), and more resources to afford quality-related investments (e.g. Noci, 1994), etc. Large firms also have more resources to explore new opportunities. In contrast, the advantages of small firms are associated with their greater flexibility (You, 1995) and the fact that they tend to be less bureaucratic and so more likely to use their resources efficiently (Baker and Nelson, 2005). They also respond more quickly to changing circumstances (e.g. Knight and Cavusgil, 1996). As such, the influence of size on profitability is uncertain and so we use the logarithm of total assets.

Industry performance with respect to profitability is also likely to influence individual firm profitability. Industries with high growth rates or profits offer more opportunities (Gruca and Rego, 2005). We expect these variables to have a positive effect on the dependent variable in Equation 1.

Control dummy variables for years are also included in the equation.

Previous empirical research on slack employs diverse variable definitions and methodologies. While some use absolute measures of profitability as dependent variables, others use relative measures, which are combined with independent variables that measure slack in relative or absolute terms indistinctly, as well as being indexed to industry values in some cases, together with non-indexed values. In this paper we seek to avoid any methodological flaws by defining variables in relative terms, standardizing them with year-industry means and standard deviations. However, we use nonstandardized size values because these raw data allow us to make more appropriate comparisons, as well as the logarithmic transformation.

\section{Sample}

We use COMPUSTAT data for all American industrial firms (SIC codes 2 and 3) with data from 1979 to 2009 with at least twenty years of observations in the database. We prefer to use a sample that prioritizes firms that remain in the sample for the duration. Given that most of the firms remained in the sample for all the years in 
question, the results are reliable and not likely to be influenced by changes in the sample over time or by short-lived episodes of unusual firm performance. Although such firms might reveal interesting slack behavior, we consider that a sample of firms observed over a long period provides a more appropriate dynamic approach. We do not consider firms in the services industry because of their different cost structure and business approach. Table 1 shows our sample and descriptive statistics. We start with 37,730 year-data observations from 1,453 different firms. Table 1 presents means, medians and year-data observations for the untransformed values of all the dependent and independent variables used in our study. The average $R O A$ ratio for the available 35,797 observations in the whole period is $9.3 \%$. Sales grew $15.8 \%$ on average for the available sample in the period, matched by a similar growth rate in PPE. The corresponding values for the remaining variables are also shown in Table 1.

(Insert Table 1 about here)

Given the panel data structure of our sample, assets are converted into values for the most recent year in our sample, applying the US inflation rate. As discussed, we use the logarithm of these values as an independent variable in our study.

Substantial differences between the mean and median values of most variables, especially $S_{t+1} / S_{t}, P P E S L, E Q D S L, C A S H S L, P P E_{t+1} / P P E_{t}$, and $A S S$, point to the presence of extreme values and hence the need to winsorize variables. We standardize all variables with mean and standard deviations of year and industry values, with two SIC digits. We also winsorize the top and bottom $1 \%$ of all standardized variables. However, all results remain largely unchanged with non-winsorized variables.

Given that not all the variables are available for all firms and years, as well as the delayed variables used, the sample size for our multivariate analyses ranges from 29,369 to 32,353 year-data observations with 1,420 firms (see Table 3 ).

Table 2 shows the Pearson correlations for the winsorized variables in our sample. While all the correlations are significant at $\mathrm{p}<0.01$, the coefficients are not high. The highest value is 0.5385 (correlation between FINSL and EQDSL). Moreover, the highest variance inflation factor in all the subsequent estimations performed is comparatively low: 2.40 for FINSL. Therefore, estimations are not likely to be influenced by collinearity.

(Insert Table 2 about here) 


\section{RESULTS}

\section{Estimations of Equation 1}

We perform panel data regressions on our sample, correcting for autocorrelation disturbances. The Hausman test rejects the null hypothesis of no correlation between individual effects and the explanatory variables. As the individual effects are correlated with the regressors in all the estimations, the random effects estimator is inconsistent, while the fixed effects estimator is consistent and efficient. We therefore perform panel data estimations with fixed effects.

Assuming that the results obtained with Equation 1 might be biased, given that some of the covariates may be endogenous, we check for the presence of endogeneity. The equation includes sales growth as a control variable, influencing firm profitability, but in turn it also depends on an increase in investment in productive capacity. We, therefore, include $P P E_{t+1} / P P E_{t}$ as an instrument for $S_{t+1} / S_{t}$ in Equation 1 . As can be seen in Table 2, the Pearson correlation between the two variables is, as expected, positive (0.3816) and significant. The sales growth residuals dependent on this instrument, in the fixed effects estimation, is significant at $\mathrm{p}<0.01$ when included in Equation 1, revealing the presence of expected endogenous disturbances. We then use the two-stage leastsquares within estimator, available in STATA, for the fixed effects option.

Results are shown in Table 3. Column 1 displays estimations when the dependent variable is future profitability. The model estimated presents a significant goodness of fit, with an overall R-square of $19.67 \%$. For the sake of simplicity, the coefficients for the year and firm dummies are not displayed. As far as the control variables are concerned, firm and industry sales growth have, as expected, significant positive influences on future profitability.

\section{(Insert Table 3 about here)}

As for our variables of interest, absorbed slack has a significant (at $p<0.01$ ) and negative influence on profitability (see column 1 in Table 3), revealing the prevalence of the inefficiency effect. A plausible explanation for this prevalence is the need to apply increasing resources to remain competitive over time. The greater within-firm R- 
square value (0.3271) compared to the overall R-square value for this estimation provides further support for this explanation. The explanation is also in keeping with increasing globalization and greater exposure to foreign competition that reduce profitability (e.g. Katics and Petersen, 1995; Ghosal, 2002), and the subsequent need for complexity involving lower profitability (e.g. Miller and Vollmann, 1985; Banker et al., 1995) and for management innovations to avoid even greater reductions in profitability (Kinney and Wempe, 2002). Additionally, absorbed slack serves primarily for continuing to expand current business, and as such is detrimental to profitability. Our results suggest that few absorbed resources can actually be applied to create synergies through the sharing of resources with other businesses, and that they cannot be applied for redeployment in more profitable business. Absorbed slack is constrained and restricted to specific current uses. The coefficients for unabsorbed slack are significantly positive for FINSL, negative but not significant for EQDSL and significantly negative (0.0992) for CASHSL, but they present values that are much less negative than the corresponding coefficients for absorbed slack (ranging from -0.201 to -0.391). Given that all the dependent and slack variables are standardized, the coefficients allow direct comparisons to be made between them. This table also displays the overall influence of absorbed and unabsorbed slack variables at time $t$ on profitability at time $t+1$. The sum of the coefficients of all the absorbed slack variables is -0.839 (significant at $\mathrm{p}<0.01$ ), which is considerably lower value than the corresponding sum of all the unabsorbed slack variables $(-0.00006$, non-significant at $p<0.1)$. The Wald test for the joint effect of both groups of variables reveals a significant (at $p<0.01$ ) lower negative influence of unabsorbed slack on profitability than that of absorbed slack. The difference is significant (at $\mathrm{p}<0.01$ ) for all individual comparisons (nine out of nine) between the three indicators of absorbed and unabsorbed slack. These results support Hypothesis 1.

We also perform analyses on longer term future profitability. Assuming that converting organizational slack, and slack resources in general, into profitability might take much longer time than our analysis provides for at time $t+1$, we analyze the impact of slack at time $t$ on profitability at time $t+3$. The results (see column 2 in Table 3 ) are largely similar to those reported in column 1 . Together with firm and industry sales growth, size significantly influences higher profitability at time $t+3$. Despite EQDSL has a significant negative influence on the dependent variable, again absorbed slack has a more negative influence on future profitability, considering all coefficients as well as the joint effect of both groups of slack. The sum of the coefficients of all the absorbed 
slack variables is -0.571 , which is considerably lower value than the corresponding sum of all the unabsorbed slack variables (-0.1086). The Wald test for the joint effect of both groups of variables reveals a significant (at $p<0.01$ ) lower negative influence of unabsorbed slack on profitability than that of absorbed slack. Again, the difference is significant (at $\mathrm{p}<0.01$ ) for all individual comparisons between the three indicators of absorbed and unabsorbed slack.

\section{Additional analysis}

Capacity is an additional factor influencing business performance and resource redeployment. Redeployability is a property of a certain type of resource and, according to Sakhartov and Folta (2014), is only pertinent for resources of limited capacity. Given these considerations we wonder whether the amount of slack affects the effect of slack on profitability.

We distinguish firms with little slack using interaction variables of slack with a dummy variable $D L$ indicating that the slack of a given firm is below the median industry-year (taking a value of 1 or zero otherwise), with $d$ indicating the subscript for these variables. We thus formulate the following enlarged model:

$$
\begin{gathered}
R O A_{i, t+1}=\alpha_{0}+\sum_{j=1}^{J} \alpha_{j} \cdot S L_{i, t}+\sum_{j=1}^{D} \alpha_{d} \cdot D L_{i, t} \cdot S L_{i, t}+\alpha_{s} \cdot \frac{S_{i, t+1}}{S_{i, t}}+\alpha_{z} \cdot \log A S S_{i, t}+\alpha_{r} \\
\cdot I P R_{i, t}+\alpha_{c} \cdot I S C_{i, t+1}+\sum_{t=1}^{T} \alpha_{t} \cdot Y_{i, t}+\varepsilon_{i, t}
\end{gathered}
$$

Column 1 in Table 4 shows the results for the impact of slack at time $t$ on profitability at time $t+1$ with the full model, including the interaction variables for low slack levels. In two of the absorbed slack variables, resource scarcity stresses its negative impact on profitability. The exception is $S G A S L$, which is a less constrained resource than INVSL and PPESL. SGASL is an indicator of the managerial and organizational resources that can be shared across businesses, and which are less likely to be used in redeployment. Firms with bottom-end managerial and organizational resources are more troubled by specific, daily operational tasks. An additional 
endowment of these resources allows organizational, planning and strategic activities, eventually enabling firms to explore new business opportunities as well as to share organizational capabilities across different current businesses, which eventually have a positive influence on profitability. For two of the unabsorbed slack variables, resource scarcity moderates the negative impact on profitability, with the $D L \cdot F I N S L$ coefficient sign being negative and only significant at $\mathrm{p}<0.1$, and it also moderates the positive sign of FINSL. The overall impact on profitability is negative for absorbed slack $(-0.915$, significant at $\mathrm{p}<0.01)$ and positive for unabsorbed slack $(0.0971$, significant at $\mathrm{p}<0.01)$ in firms with below median slack considering the sum of all coefficients $\left(\alpha_{j}+\alpha_{d}\right)$, as can be seen in Table 4. In all pairs of comparisons (nine out of nine) the effect is more favorable for unabsorbed than absorbed slack in these firms. Comparing only the interaction variables, this relationship holds for the joint effect of all variables (the total for the absorbed slack coefficients is -0.111 , while for the unabsorbed slack is 0.1174 ), as well as for six out of nine pairs of comparisons at $\mathrm{p}<0.01$ (and for seven out of nine pairs of comparisons at $\mathrm{p}<0.05$ ). However, there are no significant differences between the interaction variables of unabsorbed and absorbed slack on profitability for INVSL vs. FINSL or for SGASL vs. EQDSL.

(Insert Table 4 about here)

Overall these results suggest that firms with scarce resources would be better advised to withdraw them from current unprofitable or unviable businesses and redeploy them in new opportunities, offering better profitability prospects. In the case of scarce constrained resources, firms with little slack are less likely to face environmental threats, and given the limitations of absorbed slack, they would be unable to redeploy these resources in order to exploit better opportunities. Firms with scarce nonconstrained resources are also ill-equipped to develop new capabilities, but these resources would allow them to explore new opportunities. Given their scarcity, firms are better advised to break the inertia of their current business than are firms with plenty of resources. Firms endowed with plenty of non-constrained resources are less likely to explore alternative businesses or even to explore them while at the same time maintaining their current business. Indeed, they would be more likely to maintain their current inefficiencies. Our results suggest that low levels of unabsorbed slack seem to have a moderating effect when the relationship between slack and profitability is 
negative. In fact, the joint effect of unabsorbed slack on profitability is positive in firms with low slack. Overall, the differential effects of both types of slack on profitability is greater for firms with less slack than for firms with more, which is presumably attributed to their differential suitability for redeployment. These results provide insights and hints on this assumption, but more in-depth research is needed on this issue.

Column 2 in Table 4 displays results for Equation 2 when the dependent variable is profitability at time $t+3$, which present some differences in the interaction variables. Overall, the distance between the influence of absorbed and unabsorbed slack on profitability is greater for firms with low slack levels, with respect to the whole sample, but it is non-significant.

\section{CONCLUSIONS}

In this study we have analyzed the impact of absorbed and unabsorbed slack, measured using three different indicators of each type, on future firm profitability. Absorbed and unabsorbed slack provide valuable indications as to the most likely redeployment of resources. Thus, absorbed slack is associated with resources whose use is largely restricted to current operations and business. As a result of these strict limitations these resources are less available than unabsorbed slack for redeployment in exploiting new opportunities. In contrast, there are fewer restrictions on the use of unabsorbed slack for these alternative uses. Accordingly, we have formulated a hypothesis concerning the differential effects of absorbed vs. unabsorbed slack on firm profitability, which appear to be linked to their differential use for resource redeployment.

We find that absorbed slack has a negative influence on future profitability, which appears to reflect the need firms have to apply increasing amounts of resources to remain competitive over time, as well the difficulties they face to redeploy these resources to new uses. Indeed, the increasing levels of such resources required to maintain an on-going business are a source of inefficiency. At the same time, we find positive, negative and non-significant relationships between unabsorbed slack and future profitability. In all instances we find its influence to be more favorable, or less negative, than that of absorbed slack. This differential effect can be attributed to the 
greater possibilities for redeploying unabsorbed slack to more promising business opportunities, as well as to its ability to achieve synergies through resource sharing across different businesses.

We find evidence of the differential influences of absorbed vs. unabsorbed slack on future profitability in firms with lower levels of slack. Our results suggest that given that firms with limited capacity are obliged to withdraw resources from current business and redeploy them to exploit more attractive opportunities, and that absorbed slack is more restricted for use in current business, firms with little unabsorbed slack deviate even further away from the inertia of current business. This comparatively beneficial effect may be attributed to the lower constraints on unabsorbed slack for redeployment to more favorable opportunities than those provided by current business, as well as to achieving synergies.

Our analysis presents several limitations. We use absorbed and unabsorbed slack as indicators of exploration and exploitation, expansion, sharing and redeployment; however, we do not actually observe redeployment or synergy taking place, so our results are somewhat conjectural. There may indeed be other explanations as to why slack influences future profitability, which we cannot rule out. Future research is needed using precise measures of resource redeployment and synergy. Additionally, we do not take into account specific circumstances such as market stagnation, expansion, dynamism or munificence, nor diversification in related or unrelated businesses. Further research needs to address specific contexts and circumstances. 


\section{REFERENCES}

Alvarez, R., and G. Crespi, 2003, "Determinants of Technical Efficiency in Small Firms". Small Business Economics, 20: 233-244.

Anderson, M.C., R.D. Banker and S. Janakiraman, 2003, "Are selling, general and administrative costs sticky?" Journal of Accounting Research, 41: 47-63.

Baker, T. and R.E. Nelson, 2005, "Creating something from nothing: resource construction through entrepreneurial bricolage". Administrative Science Quarterly, 50: 329-366.

Banker, R.D., G. Potter and R.G. Schroeder, 1995, An empirical analysis of manufacturing overhead cost drivers. Journal of Accounting and Economics, 19: 115-137.

Baum, J.A.C., 1996. Organizational ecology. In Handbook of Organization Studies, Clegg S, Hardy C, Nord W (eds). Sage: London; 77-113.

Beck, T., and A. Demirguc-Kunt, 2006, "Small and Medium-Size Enterprises: Access to Finance as a Growth Constraint”. Journal of Banking and Finance, 30: 29312943.

Bercovitz, J., and W. Mitchell, 2007, "When is more better? The impact of business scale and scope on long-term business survival, while controlling for profitability". Strategic Management Journal, 28: 61-79.

Bourgeois, L., 1981, “On the measurement of organizational slack". Academy of Management Review, 6: 29-39.

Bradley, S.W., J. Wiklund and D.A. Shepherd, 2011a, "The importance of slack for new organizations facing "tough" environments". Journal of Management Studies, 48: 1071-1097.

Bradley, S.W., J. Wiklund and D.A. Shepherd, 2011b, "Swinging a double-edged sword: the effect of slack on entrepreneurial management and growth". Journal of Business Venturing, 26: 537-554.

Capron, L., Dussauge, P., and W. Mitchell, 1998, "Resource redeployment following horizontal acquisitions in Europe and North America, 1988-1992”. Strategic Management Journal, 19: 631-661.

Caves, R.E. and D. Barton, 1990, Efficiency in US Manufacturing Industries. Cambridge: MIT Press. 
Cyert, R., and J. March, 1956, "Organizational factors in the theory of oligopoly". Quarterly Journals of Economics, 70: 44-64.

Damanpour, F., 1987, “The adoption of technological, administrative, and ancillary innovations: Impacts of organizational factors”. Journal of Management, 13: 675688.

Daniel, F., F.T. Lohrke, C.J. Fornaciari and R.A. Turner, Jr., 2004, "Slack resources and firm performance: a meta-analysis". Journal of Business Research, 57: $565-574$.

George, G., 2005, "Slack resources and the performance of privately held firms". Academy of Management Journal, 48: 661-676.

Ghosal V., 2002, "Potential foreign competition in U.S. manufacturing”. International Journal of Industrial Organization 20: 1461-1489.

Greve, H.R., 2003, Organizational Learning from Performance Feedback: a Behavioral Perspective on Innovation and Change. Cambridge: Cambridge University Press.

Gruca, T.S., and L.L. Rego, 2005, "Customer satisfaction, cash flow, and shareholder value". Journal of Marketing, 69: 115-130.

Helfat, C.E., and K.M. Eisenhart, 2004, "Inter-temporal economies of scope, organizational modularity, and the dynamics of diversification". Strategic Management Journal, 25: 1217-1232.

Hendricks, K.B., V.R. Singha and R. Zhang, 2009, "The effects of operational slack, diversification, and vertical relatedness on the stock market reaction to supply chain disruptions". Journal of Operations Management, 27: 233-246.

Huang, J.W., and Y.H. Li, 2012, Slack resources in team learning and project performance. Journal of Business Research, 65: 381-388.

Katics, M.M., and B. C. Petersen, 1995, “The effect of rising import competition on market power: a panel data study of U.S. manufacturing”. Journal of Industrial Economics 42: 277-286.

Kaul, A., 2012, "Technology and corporate scope: firm and rival innovation as antecedents of corporate transactions". Strategic Management Journal, 33: 347367.

Kinney, M.R., and W.F. Wempe, 2002 "Further evidence on the extent and origins of JIT's profitability effects", Accounting Review, vol. 77(1): 203-225 
Knight, G.A., and S.T. Cavusgil, 1996, "The born global firm: A challenge to traditional internationalization theory". Advances in International Marketing, 8: 11-26.

Kraatz, M.S., and E.J. Zajac, 2001, "How organizational resources affect strategic change and performance in turbulent environments: theory and evidence". Organization Science, 12(5): 632-657.

Lin, W., Cheng, K. and Y. Liu, 2001, Organizational slack and firm's internationalization: a longitudinal study of high-technology firms. Journal of World Business, 44(2): 397-406.

Love, E.G., and N. Nohria, 2005, "Reducing slack: the performance consequences of downsizing by large industrial firms, 1997-93”. Strategic Management Journal, 26: $1087-1108$.

Martinelli, C., 1997, Small firms, borrowing constraints, and reputation. Journal of Economic Behavior and Organization, 33, 91-105.

Matusaka, J.G., 2001, "Corporate diversification, value maximization, and organizational capabilities”. Journal of Business, 74(3): 409-431.

Mellahi, K., and A. Wilkinson, 2010, "A study of the association between level of slack reduction following downsizing and innovation output". Journal of Management Studies, 47: 483-508.

Miller, J.G., and T.E. Vollman, 1985, "The hidden factory". Harvard Business Review, September-October: 142-150.

Mishina, Y., T.G. Pollock and J.F. Porac, 2004, "Are more resources always better for growth? Resource stickiness in market and product expansion". Strategic Management Journal, 25: 1179-1197.

Mitchell, W., 1994. The dynamics of evolving markets: the effects of business sales and age on dissolutions and divestitures. Administrative Science Quarterly 39(4): 575-602.

Modi, S.B., and S. Mishra, 2011, "What drives financial performance - resource efficiency or resource slack? Evidence from U.S. based manufacturing firms from 1991 to 2006". Journal of Operations Management, 29: 254-273.

Montgomery, C.A., and B. Wernefelt, 1988, "Diversification, Ricardian rents and Tobin's q". Rand Journal of Economics, 19(4): 623-632. 
Noci, G., 1994, “Accounting and non-accounting measures of quality-based performances in small firms". International Journal of Operations and Production Management, 15: 78-105.

O'Brien, J.P. and T.B. Folta, 2005, “A transaction cost perspective on why, how, and when cash impacts firm performance". Managerial and Decision Economics, 30(7): 465-479.

Peng, M.W., Y. Li, E. Xie and Z. Su, 2010, “CEO duality, organizational slack, and firm performance in China". Asia Pacific Journal of Management, 27: 611-624.

Penrose, E., 1995, The theory of the growth of the firm. New York: Wiley.

Phan, P. and C. Hill, 1995, "Organizational restructuring and economic performance in leveraged buyouts: an ex-post study". Academy of Management Journal, 38: 704739.

Sakhartov, A.V., and T.B. Folta, 2014, "Resource relatedness, redeployability, and firm value". Strategic Management Journal, 35: 1781-1797.

Sharfman, M., G. Wolf, R. Chase and D. Tansik, 1988, "Antecedents of organizational slack". Academy of Management Review, 13: 691-614

Sinclair, G., Klepper, S., and W. Cohen, 2000, "What's experience got to do with it? Sources of cost reduction in a large specialty chemicals producer". Management Science, 46(1): 28-45.

Sirmon, D.G., and M.A. Hitt, 2009, "Contingencies within dynamic managerial capabilities: interdependent effects of resource investment and deployment on firm performance". Strategic Management Journal, 30: 1375-1394.

Starr, J.E., and I.C. MacMillan, 1990, "Resource cooptation via social contracting: resource acquisition strategies for new ventures”. Strategic Management Journal 11: 79-92.

Stevenson, H.H., and J.C. Jarillo, 1990, "A paradigm of entrepreneurship: entrepreneurial management”. Strategic Management Journal, 11 (special issue): $17-27$.

Su, Z., E. Xie, D. Wang and Y. Li, 2011, "Entrepreneurial strategy making, resources, and firm performance: evidence from China". Small Business Economics, 36: 235-247.

Subramanyam, R., N. Ramasubbu, and M.S. Krishnan, 2012, "In search of efficient flexibility: effects of software component granularity on development effort, defects, and customization effort”. Information Systems Research, 23: 787-803. 
Sull D.M., 1999, The dynamics of standing still: Firestone Tire \& Rubber and the radial revolution. Business History Review 73(3): 430-464.

Tan, J., 2003, "Curvilinear relationship between organizational slack and firm performance: evidence from chinese state enterprises". European Management Journal, 21(6): 740-749.

Tan, J. and M.W. Peng, 2003, "Organizational slack and firm performance during economic transitions: two studies from an emerging economy”. Strategic Management Journal, 24: 1249-1263.

Tan, J., and L. Wang, 2010, "Flexibility-efficiency tradeoff and performance implications among Chinese SOEs". Journal of Business Research, 63: 356-362.

Teece, D.J., Pisano, G., and A. Shuen, 1997. "Dynamic capabilities and strategic management". Strategic Management Journal, 17(7): 509-533.

Thompson, J.D., 1967, Organizations in Action. New York: McGraw-Hill.

Vanacker, T., V. Collewaert and I. Paeleman, 2013, "The relationship between slack resources and the performance of entrepreneurial firms: the role of venture capital and angel investors". Journal of Management Studies, 50: 1070-1096.

You, J., 1995, "Small firms in economic theory". Cambridge Journal of Economics, 19: 441-462. 
Table 1 Descriptive statistics

\begin{tabular}{lccr}
\hline & $\begin{array}{c}\text { Year-data } \\
\text { observations }\end{array}$ & \multicolumn{1}{l}{ Mean } & \multicolumn{1}{c}{ Median } \\
\hline$R O A$ & 35,797 & 0.09304 & 0.09770 \\
$S_{t+1} / S_{t}$ & 35,777 & 1.15869 & 1.07002 \\
$P P E_{t+1} / P P E_{t}$ & 35,698 & 1.16188 & 1.03755 \\
$A S S^{*}$ & 37,454 & $4,300.72$ & 296.00 \\
Absorbed slack: & & & \\
$I N V S L$ & 37,369 & 0.22370 & 0.15214 \\
$P P E S L$ & 37,367 & 0.59664 & 0.21563 \\
SGASL & 35,298 & 0.24347 & 0.21917 \\
Unabsorbed slack: & & & \\
FINSL & 36,848 & 0.27520 & 0.28393 \\
EQDSL & 36,918 & 2.07415 & 1.15805 \\
CASHSL & 36,762 & 0.12392 & 0.06567 \\
\hline
\end{tabular}

Notes:

* Constant values: $000 \$$. ROA = return on assets, $S=$ sales, $I N V S L=$ inventory slack, $P P E S L=$ property, plant and equipment slack, $S G A S L=$ selling, general and administration slack, FINSL = financial slack, $E Q D S L=$ equity-to-debt slack, $C A S H S L=$ cash slack, $P P E=$ property, plant and equipment, and $A S S=$ total assets. 
Table 2 Pearson correlations

\begin{tabular}{|c|c|c|c|c|c|c|c|c|c|c|c|}
\hline & INVSL & PPESL & SGASL & FINSL & $E Q D S L$ & CASHSL & $S_{t+1} / S_{t}$ & $\ln A S S$ & $I P R$ & $I S C$ & $P P E_{t+1} / P P E_{t}$ \\
\hline INVSL & 1 & & & & & & & & & & \\
\hline PPESL & $0.0267 * * *$ & 1 & & & & & & & & & \\
\hline$S G A S L$ & $0.1327 * * *$ & $-0.1343 * * *$ & 1 & & & & & & & & \\
\hline FINSL & $0.2243^{* * *}$ & $-0.2848 * * *$ & $0.1436^{* * *}$ & 1 & & & & & & & \\
\hline$E Q D S L$ & $0.036^{* * *}$ & $-0.0247 * * *$ & $0.1059^{* * *}$ & $0.5385^{* * *}$ & 1 & & & & & & \\
\hline CASHSL & $-0.0344 * * *$ & $0.1107 * * *$ & $0.1889 * * *$ & $0.3517 * * *$ & $0.4362 * * *$ & 1 & & & & & \\
\hline$S_{t+1} / S_{t}$ & $0.0716^{* * *}$ & $0.0882 * * *$ & $0.0656^{* * *}$ & $0.0328 * * *$ & $0.0339 * * *$ & $0.1177 * * *$ & 1 & & & & \\
\hline $\ln A S S$ & $-0.1424 * * *$ & $0.1776^{* * *}$ & $-0.2345^{* * *}$ & $-0.2445 * * *$ & $-0.1876^{* * *}$ & $-0.0591 * * *$ & $-0.0675^{* * *}$ & 1 & & & \\
\hline$I P R$ & 0.0036 & 0.0035 & 0.0002 & $-0.0126^{* *}$ & 0.004 & 0.0009 & 0.0003 & 0.0024 & 1 & & \\
\hline$I S C$ & -0.0007 & -0.0086 & -0.0023 & 0 & -0.0067 & -0.0066 & $-0.3157 * * *$ & -0.0069 & $0.0230 * * *$ & 1 & \\
\hline$P P E_{t+1} / P P E_{t}$ & $-0.039 * * *$ & $-0.0735 * * *$ & $-0.0122 * *$ & $0.1247^{* * *}$ & $0.0922 * * *$ & $0.096^{* * *}$ & $0.3816^{* * *}$ & $-0.0456^{* * *}$ & 0.0011 & -0.0059 & 1 \\
\hline
\end{tabular}

Notes: * ** and *** indicate significance at the 10 per cent, 5 per cent and 1 per cent levels based on two-tailed tests, respectively. INVSL $=$ inventory slack, PPESL = property, plant and equipment slack, SGASL = selling, general and administration slack, FINSL= financial slack, EQDSL = equity-todebt slack, CASHSL = cash slack, $\mathrm{S}=$ sales, $\mathrm{ASS}=$ total assets, $I P R=$ mean industry profitability, $I S C=$ mean industry sales growth, and $P P E=$ property, plant and equipment. 
Table 3 Impact of slack at time $t$ on profitability at time $t+\mathrm{n}$ (t-statistics in parentheses). Fixed effects estimations for Equation 1 correcting for endogeneity (two-stage leastsquares within estimator).

\begin{tabular}{|c|c|c|}
\hline VARIABLES & $\begin{array}{c}(1) \\
R O A_{t+1} \\
\end{array}$ & $\begin{array}{c}(2) \\
R O A_{t+3} \\
\end{array}$ \\
\hline \multicolumn{3}{|l|}{ Absorbed slack: } \\
\hline INVSL & $\begin{array}{l}-0.247 * * * \\
(0.00662)\end{array}$ & $\begin{array}{l}-0.155^{* * *} \\
(0.00540)\end{array}$ \\
\hline PPESL & $\begin{array}{l}-0.201 * * * \\
(0.00751)\end{array}$ & $\begin{array}{l}-0.156 * * * \\
(0.00634)\end{array}$ \\
\hline$S G A S L$ & $\begin{array}{l}-0.391 * * * \\
(0.00759)\end{array}$ & $\begin{array}{l}-0.260 * * * \\
(0.00649)\end{array}$ \\
\hline \multicolumn{3}{|l|}{ Unabsorbed slack: } \\
\hline FINSL & $\begin{array}{l}0.108 * * * \\
(0.00674)\end{array}$ & $\begin{array}{r}0.0379 * * * \\
(0.00566)\end{array}$ \\
\hline$E Q D S L$ & $\begin{array}{l}-0.00886 \\
(0.00660)\end{array}$ & $\begin{array}{c}-0.0503 * * * \\
(0.00558)\end{array}$ \\
\hline CASHSL & $\begin{array}{l}-0.0992 * * * \\
(0.00696)\end{array}$ & $\begin{array}{c}-0.0962 * * * \\
(0.00582)\end{array}$ \\
\hline \multicolumn{3}{|l|}{ Control variables: } \\
\hline $\begin{array}{l}S_{t+1} / S_{t} \text { (mean three years ahead } \\
\left.\text { for } R O A_{t+3}\right)\end{array}$ & $1.811 * * *$ & $2.642 * * *$ \\
\hline & $(0.0394)$ & $(0.0433)$ \\
\hline $\log A S S$ & $\begin{array}{l}-0.0124 \\
(0.0145)\end{array}$ & $\begin{array}{c}0.0827 * * * \\
(0.0142)\end{array}$ \\
\hline$I P R$ & $\begin{array}{l}-0.257 \\
(0.157)\end{array}$ & $\begin{array}{l}-0.131 \\
(0.130)\end{array}$ \\
\hline ISC & $\begin{array}{c}0.560 * * * \\
(0.0191)\end{array}$ & $\begin{array}{c}0.911 * * * \\
(0.0257)\end{array}$ \\
\hline Constant & $\begin{array}{c}-0.537 * * * \\
(0.0530)\end{array}$ & $\begin{array}{c}-1.143^{* * *} \\
(0.0556)\end{array}$ \\
\hline Observations & 32,353 & 29,369 \\
\hline Number of firms & 1,420 & 1,417 \\
\hline R-sq overall & 0.1967 & 0.2010 \\
\hline FIRM & YES & YES \\
\hline YEAR & YES & YES \\
\hline Joint effects: & & \\
\hline Absorbed slack $\left(\sum \alpha_{j}\right)$ & $-0.839 * * *$ & $-0.571 * * *$ \\
\hline Unabsorbed slack $\left(\sum \alpha_{j}\right)$ & -.00006 & $-0.1086^{* * *}$ \\
\hline Difference: abs. - unabs. $\left(\sum \alpha_{j}\right)$ & $-0.83894 * * *$ & $-0.4624 * * *$ \\
\hline
\end{tabular}

Notes: Standard errors in parentheses. Significance: $* * * \mathrm{p}<0.01, * * \mathrm{p}<0.05,{ }^{*} \mathrm{p}<0.1$. $R O A=$ return on assets, INVSL $=$ inventory slack, PPESL $=$ property, plant and equipment slack, $S G A S L=$ selling, general and administration slack, FINSL= financial slack, $E Q D S L=$ equity-to-debt slack, $C A S H S L=$ cash slack, $S=$ sales, $A S S=$ total assets, $I P R=$ mean industry profitability, $I S C=$ mean industry sales growth, and $\alpha_{j}=$ coefficients of slack variables. 
Table 4 Impact of slack at time $t$ on profitability at time $t+\mathrm{n}$ (t-statistics in parentheses). Fixed effects estimations for Equation 2 correcting for endogeneity (two-stage least-squares within estimator).

\begin{tabular}{|c|c|c|}
\hline VARIABLES & $\begin{array}{c}(1) \\
R O A_{t+1} \\
\end{array}$ & $\begin{array}{c}(2) \\
R O A_{t+3} \\
\end{array}$ \\
\hline \multicolumn{3}{|l|}{ Absorbed slack: } \\
\hline INVSL & $\begin{array}{l}-0.221 * * * \\
(0.00816)\end{array}$ & $\begin{array}{r}-0.152 * * * \\
(0.00667)\end{array}$ \\
\hline$D L \cdot I N V S L$ & $\begin{array}{c}-0.0680 * * * \\
(0.0167)\end{array}$ & $\begin{array}{r}-0.00380 \\
(0.0140)\end{array}$ \\
\hline PPESL & $\begin{array}{c}-0.163 * * * \\
(0.00869)\end{array}$ & $\begin{array}{c}-0.126 * * * \\
(0.00727)\end{array}$ \\
\hline$D L \cdot P P E S L$ & $\begin{array}{c}-0.163 * * * \\
(0.0195)\end{array}$ & $\begin{array}{c}-0.129 * * * \\
(0.0166)\end{array}$ \\
\hline$S G A S L$ & $\begin{array}{l}-0.420 * * * \\
(0.00929)\end{array}$ & $\begin{array}{c}-0.279 * * * \\
(0.00795)\end{array}$ \\
\hline$D L \cdot S G A S L$ & $\begin{array}{c}0.120 * * * \\
(0.0201)\end{array}$ & $\begin{array}{c}0.0809 * * * \\
(0.0170)\end{array}$ \\
\hline \multicolumn{3}{|l|}{ Unabsorbed slack: } \\
\hline FINSL & $\begin{array}{c}0.111 * * * \\
(0.0120)\end{array}$ & $\begin{array}{c}0.0433 * * * \\
(0.0101)\end{array}$ \\
\hline$D L \cdot F I N S L$ & $\begin{array}{c}-0.0296^{*} \\
(0.0164)\end{array}$ & $\begin{array}{l}-0.00847 \\
(0.0137)\end{array}$ \\
\hline EQDSL & $\begin{array}{c}-0.0233 * * * \\
(0.00738)\end{array}$ & $\begin{array}{c}-0.0388 * * * \\
(0.00621)\end{array}$ \\
\hline$D L \cdot E Q D S L$ & $\begin{array}{c}0.0834 * * * \\
(0.0186)\end{array}$ & $\begin{array}{c}-0.0698 * * * \\
(0.0157)\end{array}$ \\
\hline CASHSL & $\begin{array}{c}-0.108 * * * \\
(0.00754)\end{array}$ & $\begin{array}{c}-0.106 * * * \\
(0.00630)\end{array}$ \\
\hline$D L \cdot C A S H S L$ & $\begin{array}{c}0.0636^{* * *} \\
(0.0197)\end{array}$ & $\begin{array}{c}0.0617^{* * *} \\
(0.0165)\end{array}$ \\
\hline \multicolumn{3}{|l|}{ Control variables: } \\
\hline$S_{t+1} / S_{t}\left(\right.$ mean three years ahead for $\left.R O A_{t+3}\right)$ & $\begin{array}{c}1.772 * * * \\
(0.0393)\end{array}$ & $\begin{array}{c}2.610^{* * *} \\
(0.0430)\end{array}$ \\
\hline $\log A S S$ & $\begin{array}{r}-0.00430 \\
(0.0146)\end{array}$ & $\begin{array}{c}0.0897 * * * \\
(0.0142)\end{array}$ \\
\hline$I P R$ & $\begin{array}{c}-0.238 \\
(0.156)\end{array}$ & $\begin{array}{l}-0.143 \\
(0.130)\end{array}$ \\
\hline ISC & $\begin{array}{c}0.559 * * * \\
(0.0191)\end{array}$ & $\begin{array}{c}0.922 * * * \\
(0.0259)\end{array}$ \\
\hline Constant & $\begin{array}{c}-0.557 * * * \\
(0.0554)\end{array}$ & $\begin{array}{c}-1.188^{* * *} \\
(0.0579)\end{array}$ \\
\hline Observations & 32,353 & 29,369 \\
\hline Number of firms & 1,420 & 1,417 \\
\hline R-sq overall & 0.2082 & 0.2082 \\
\hline Firm & YES & YES \\
\hline Year & YES & YES \\
\hline $\begin{array}{l}\text { Joint effects: } \\
\text { Absorbed slack: low slack }\left(\sum \alpha_{j}+\sum \alpha_{d}\right)\end{array}$ & $-0.915 * * *$ & $-0.6089 * * *$ \\
\hline
\end{tabular}


Unabsorbed slack: low slack $\left(\sum \alpha_{j}+\sum \alpha_{d}\right)$

Difference low slack: abs. - unabs. $\left(\sum \alpha_{j}+\sum \alpha_{d}\right)$

Absorbed slack: interaction variables $\left(\sum \alpha_{d}\right)$

Unabsorbed slack: interaction variables $\left(\sum \alpha_{d}\right)$

Difference interaction variables: abs. - unabs. $\left(\sum \alpha_{d}\right)$
$0.0971 * * * \quad-0.1807 * * *$

$1.0121 * * * \quad-0.4282 * * *$

$-0.111 * * * \quad-0.0519 * *$

$0.1174 * * * \quad-0.0165$

$-0.2284 * * * \quad-0.0353$

Notes: Standard errors in parentheses. Significance: $* * * \mathrm{p}<0.01, * * \mathrm{p}<0.05, * \mathrm{p}<0.1 . R O A=$ return on assets, $I N V S L=$ inventory slack, $P P E S L=$ property, plant and equipment slack, $S G A S L=$ selling, general and administration slack, FINSL = financial slack, EQDSL = equity-to-debt slack, $C A S H S L$ = cash slack, $S=$ sales, $A S S=$ total assets, $I P R=$ mean industry profitability, $I S C=$ mean industry sales growth (mean last three years when estimating $R O A_{t+3}$ ), $\alpha_{j}=$ coefficients of slack variables, and $\alpha_{d}=$ coefficients of interaction variables with slack. 
Figure 1 Relationship between slack and resource constraints.

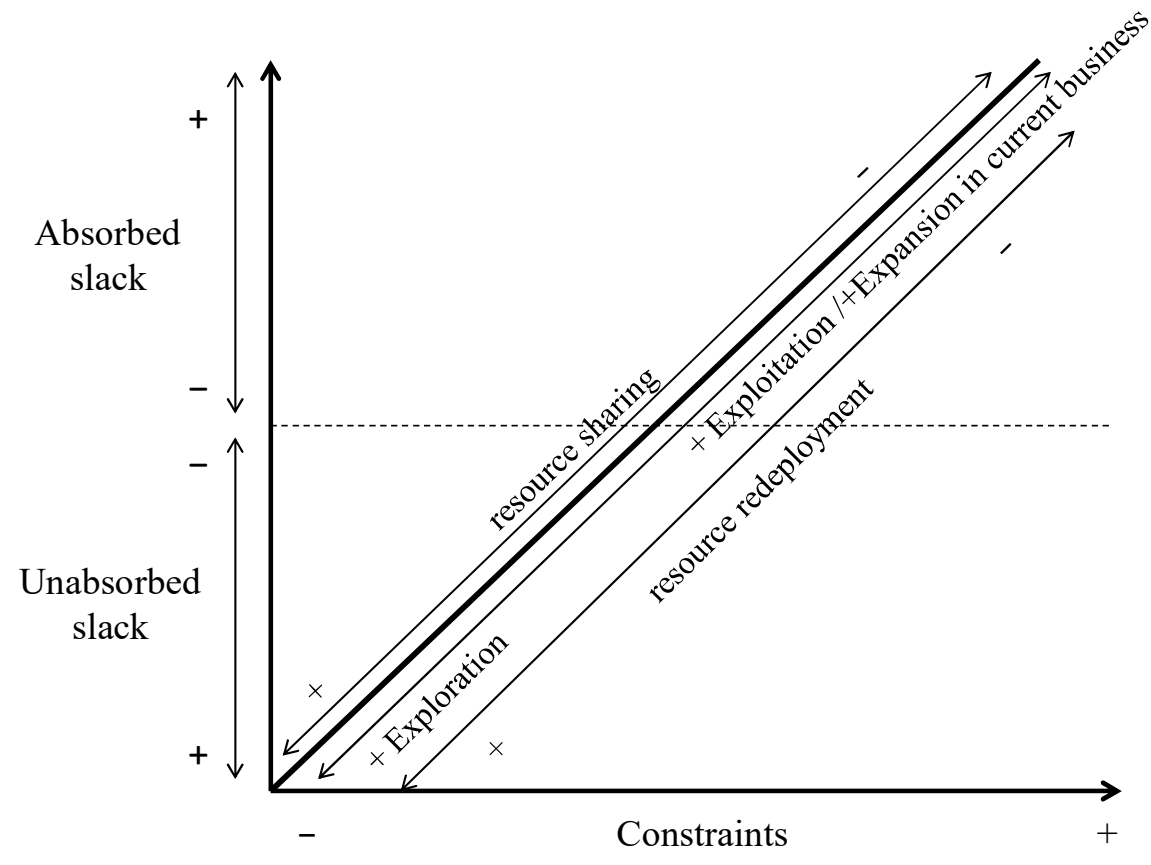

The thick bold line represents the overall relationship between resource constraints and slack, while the thin lines represent specific relationships with respect to exploration/exploitation, resource sharing and resource redeployment. 